\title{
TRATAMENTO DE EFLUENTE DE LAVANDERIA HOSPITALAR POR COAGULAÇÃO/FLOCULAÇÃ̃O SEGUIDA DE ADSORÇÃO VISANDO AO SEU REUSO
}

\author{
J. P. ZOTESSO ${ }^{1 *}$, J. F. HONORIO ${ }^{1}$, E.S. $\operatorname{COSSICH}^{1}$, C. R. G. TAVARES ${ }^{1}$ \\ ${ }^{1}$ Universidade Estadual de Maringá, Departamento de Engenharia Química \\ e-mail: jaquelinepz@hotmail.com
}

\begin{abstract}
RESUMO
Os efluentes gerados pelo processamento de roupas em lavanderias hospitalares representam uma mistura complexa, resultante dos produtos inseridos durante a lavagem e da carga orgânica e inorgânica proveniente da sujidade das roupas lavadas. Dada a sua peculiaridade e elevada geração, diversas pesquisas têm sido realizadas em busca de alternativas de tratamento para esses efluentes, inclusive para fins de reuso no próprio processo de lavagem. Nesse sentido, o presente trabalho teve como objetivo avaliar a eficiência do sistema de tratamento composto por coagulação/floculação, seguida de adsorção em carvão ativado, aplicado ao efluente da lavanderia do Hospital Universitário Regional de Maringá (HUM), visando ao seu reuso. Na coagulação/floculação, sulfato de alumínio foi utilizado como coagulante, sendo testado em concentrações de 100 a $600 \mathrm{mg} \mathrm{L}^{-1}$ e em diferentes valores de $\mathrm{pH}(5,7$ e 9). A adsorção foi realizada com o efluente pré-tratado por coagulação/floculação, em diferentes valores de $\mathrm{pH}$, utilizando-se três tipos de carvão ativado: babaçu, dendê e osso bovino. O processo de coagulação/floculação permitiu a redução dos parâmetros cor e turbidez aos níveis desejados. Ao final do sistema combinado de tratamento, o maior percentual de remoção de DQO foi $57,8 \%$, obtido com a adsorção em carvão de osso bovino. Ainda assim, essa redução não foi suficiente para se alcançar o limite de DQO estabelecido para reuso do efluente no próprio processo de lavagem, no entanto, o reuso para fins menos nobres pode ser considerado.
\end{abstract}

\section{INTRODUÇÃO}

Os hospitais consomem significativo volume de água diariamente, que varia de acordo com as atividades desempenhadas e serviços oferecidos pelo estabelecimento. Consequentemente, o volume de efluente gerado também é bem variável, sendo de 200 a $1200 \mathrm{~L}_{\text {leito }}{ }^{-1} \mathrm{dia}^{-1}$ (VERLICCHI et al., 2010).

No Brasil, é permitido que efluentes hospitalares sejam lançados diretamente na rede coletora de esgotos. Apenas nos casos em que a unidade hospitalar está localizada em uma região onde não há rede coletora de esgoto, os efluentes devem receber tratamento antes de serem lançados nos cursos d'água, de acordo com a Resolução CONAMA $\mathrm{n}^{\circ}$ 430/2011, que estabelece as condições e padrões de lançamento de efluentes (BRASIL, 2011).

Estima-se que cerca de metade da água consumida em hospitais é destinada às atividades das lavanderias, que utilizam entre 35 a $40 \mathrm{~L}$ de água para cada $\mathrm{kg}$ de roupa seca processada (BRASIL, 1986).

Assim como os efluentes hospitalares, o efluente gerado especificamente pelo processamento de roupas em estabelecimentos de saúde representa uma 
mistura complexa, resultante dos produtos inseridos durante a lavagem e da sujidade das roupas.

Dada a sua peculiaridade e elevada geração, é crescente o número de pesquisas que vêm sendo realizadas em busca de possíveis alternativas de tratamento para esses efluentes.

\subsection{Tratamento de Efluentes de Lavanderias Hospitalares}

Estudos propondo sistemas de tratamento para efluentes hospitalares normalmente se baseiam no efluente final gerado por esses estabelecimentos, ou seja, sem distinção entre os diversos setores que o constituem (laboratórios, lavanderia, cozinha, clínicas etc.) (KOVALOVA et al., 2012; LIU et al., 2010).

Especificamente em relação ao tratamento de efluentes gerados em lavanderias hospitalares, algumas pesquisas têm por objetivo apenas alcançar os padrões de descarte de efluentes, conforme a legislação local vigente (CIABATTI et al., 2009; KIST, ALBRECHT e MACHADO, 2008), enquanto outras já abordam o tratamento para fins de reuso (SOUZA, 2012).

A maioria dos estudos disponíveis na literatura relata a aplicação de processos oxidativos avançados no tratamento de efluentes de lavanderias hospitalares. Entretanto, tais processos, quando utilizados exclusivamente, não proporcionam reduções significativas dos parâmetros de carga (KERN et al., 2013; KIST, ALBRECHT e MACHADO, 2008; SOUZA, 2012).

De fato, o tratamento de efluentes de lavanderias é particularmente difícil devido à combinação da elevada concentração de surfactantes com a carga orgânica e inorgânica proveniente da sujidade das roupas lavadas (CIABATTI et al., 2009).

No entanto, um estudo realizado por Šostar-Turk, Petrinić e Simonič (2005) demonstrou que a combinação de tratamento convencional com adsorção em carvão ativado granular foi muito eficiente na redução dos parâmetros de carga do efluente de uma lavanderia que processa roupas hospitalares.

Esses resultados indicaram que a adsorção em carvão ativado representa uma tecnologia promissora no tratamento de efluente de lavanderia hospitalar, podendo ser inclusive aplicada para fins de reuso no próprio processo de lavagem.

\subsection{Reuso de Águas Servidas em Lavanderias}

No Brasil, ainda não existe uma regulamentação que aborde o reuso de água em lavanderias. No entanto, o "Guia de Conservação e Reuso da Água em Edificações" estabelece parâmetros físicoquímicos e microbiológicos para água de reuso classe 1, que engloba as águas tratadas destinadas ao uso em descargas de bacias sanitárias, lavagem de pisos, roupas e veículos, bem como aquelas destinadas a fins ornamentais (ANA/FIESP, SINDUSCON-SP, 2005).

Apesar de englobar diversos parâmetros físico-químicos, esse material não apresenta valores de referência para a demanda química de oxigênio (DQO), parâmetro comumente utilizado para estimar a carga poluidora em efluentes e águas naturais.

Todavia, para que efluente tratado possa ser reutilizado no próprio processo de lavagem, Ciabatti et al. (2009), em seus estudos de tratabilidade de águas servidas de lavanderias comerciais, recomendaram que o parâmetro DQO não exceda $100 \mathrm{mg} \mathrm{L}^{-1}$.

Frente ao elevado consumo de água em lavanderias hospitalares e à complexidade do efluente gerado, o reuso interno de águas servidas nesses estabelecimentos pode representar, além de economia e conservação, uma forma de se evitar os impactos advindos 
do descarte inadequado desses efluentes no ambiente.

Nesse sentido, o presente trabalho teve como objetivo avaliar a eficiência do sistema de tratamento composto por coagulação/floculação seguida de adsorção em carvão ativado, aplicado a um efluente de lavanderia hospitalar, para fins de reuso.

\section{MATERIAIS E MÉTODOS}

O efluente foi coletado na lavanderia do Hospital Universitário Regional de Maringá (HUM) e caracterizado em relação aos seguintes parâmetros: pH, cor, turbidez, DQO, alcalinidade e sólidos totais, suspensos e dissolvidos.

Todas as análises foram realizadas de acordo com as metodologias descritas no Standard Methods for the Examination of Water and Wastewarter (APHA, 1998).

A amostragem foi realizada de forma composta, durante o processo de lavagem de roupas de sujidade pesada, a fim de se obter uma amostra que representasse o efluente em seu estado mais crítico.

O processo de coagulação/floculação foi realizado para pré-tratamento do efluente da lavanderia hospitalar. Em seguida, a adsorção foi avaliada utilizando-se três carvões ativados como adsorventes, visando obter, ao final do processo, parâmetros adequados para reuso interno do efluente tratado.

\subsection{Coagulação/Floculação}

A coagulação/floculação foi realizada em equipamento Jar-Test Milan, modelo JT101. Em cada ensaio foram utilizados $200 \mathrm{~mL}$ de efluente, sendo testadas as seguintes concentrações de coagulante: 100, 200, 300, 400, 500 e $600 \mathrm{mg} \mathrm{L}^{-1}$. O coagulante utilizado foi o sulfato de alumínio $1 \%\left(\mathrm{Al}_{2}\left(\mathrm{SO}_{4}\right)_{3} \cdot 18 \mathrm{H}_{2} \mathrm{O}\right)$.

A solubilidade do sulfato de alumínio em água varia com o $\mathrm{pH}$, sendo mais baixa em $\mathrm{pH}$ entre 5 e 7 , motivo pela qual a coagulação/floculação deve ser realizada nessa faixa (RICHTER, 2009). Entretanto, optou-se por avaliar a coagulação/floculação também em $\mathrm{pH}$ 9, uma vez que o $\mathrm{pH}$ do efluente bruto é alcalino. Dessa forma, os valores de $\mathrm{pH}$ escolhidos foram 5, 7 e 9, obtidos por meio da adição de soluções diluídas de $\mathrm{H}_{2} \mathrm{SO}_{4}$.

As velocidades de mistura rápida e lenta foram, respectivamente, $120 \mathrm{rpm}$ (durante 3 min) e $15 \mathrm{rpm}$ (durante $5 \mathrm{~min}$ ). Para remoção dos flocos formados, o efluente foi filtrado em papel de filtro quantitativo faixa branca. Em seguida, avaliou-se a cor e a turbidez das amostras em espectrofotômetro $\mathrm{HACH}$, modelo DR/2010.

\subsection{Adsorção}

Os ensaios de adsorção foram realizados com o efluente pré-tratado por coagulação/floculação (item 2.1), utilizandose os seguintes adsorventes: carvão de casca de coco de babaçu (Tobasa Bioindustrial de Babaçu S.A.), carvão de casca de coco de dendê (Bahiacarbon Agro Industrial Ltda.) e carvão de osso bovino (Bonechar Carvão Ativado do Brasil Ltda.).

Os carvões de casca de coco de dendê e babaçu foram caracterizados por Ferreira et al. (2014), e as especificações técnicas do carvão de osso bovino foram fornecidas pelo fabricante (Bonechar Carvão Ativado do Brasil Ltda.) no trabalho de Monarin (2012), com exceção do $\mathrm{pH}_{\mathrm{PCZ}}$, determinado pelo autor. Esses dados foram reunidos na Tabela 1.

Tabela 1 - Características dos adsorventes.

\begin{tabular}{cccc}
\hline Parâmetro & Babaçu & Dendê & Osso \\
\hline $\begin{array}{c}\text { Área específica } \\
\text { BET } \\
\left(\mathrm{m}^{2} \mathrm{~g}^{-1}\right)\end{array}$ & 484 & 672 & 200 \\
$\begin{array}{c}\text { Volume total de } \\
\text { poros }\end{array}$ & 0,252 & 0,369 & 0,225 \\
$\begin{array}{c}\left(\mathrm{cm}^{3} \mathrm{~g}^{-1}\right) \\
\mathrm{pH}_{\text {PCZ }}\end{array}$ & 3,9 & 6,6 & 6,6 \\
\hline \multicolumn{7}{l}{ Fonte: Ferreira et al. (2014); Monarin (2012). }
\end{tabular}


A adsorção foi realizada em sistema batelada para os três carvões, avaliando-se a influência do $\mathrm{pH}$. Para tanto, os experimentos foram conduzidos sem ajuste de $\mathrm{pH}(\mathrm{pH}$ do efluente pré-tratado), e também em pH 4 e 9, ajustados pela adição de soluções diluídas de $\mathrm{H}_{2} \mathrm{SO}_{4}$.

Em cada experimento adicionou-se $0,3 \mathrm{~g}$ de adsorvente a $60 \mathrm{~mL}$ de efluente. A adsorção foi realizada em incubadora com agitação orbital a $100 \mathrm{rpm}$, com temperatura controlada de $25{ }^{\circ} \mathrm{C}$, por 2 horas.

Para remoção do carvão, o efluente foi filtrado em papel de filtro quantitativo faixa branca. Em seguida, avaliou-se a DQO do efluente tratado pelo método colorimétrico, em espectrofotômetro $\mathrm{HACH}$, modelo DR/2010.

\section{RESULTADOS E DISCUSSÃO}

A caracterização do efluente bruto foi realizada para determinação dos parâmetros físico-químicos iniciais do efluente de lavanderia hospitalar (Tabela 2).

Foram realizadas duas coletas, sendo o efluente da primeira coleta (efluente 1) utilizado para os ensaios de coagulação/floculação, e o efluente da segunda coleta (efluente 2) utilizado para os experimentos de adsorção, após prétratamento por coagulação/floculação.

Tabela 2 - Parâmetros físico-químicos do efluente bruto.

\begin{tabular}{lcc}
\hline \multicolumn{1}{c}{ Parâmetro } & $\begin{array}{c}\text { Efluente } \\
1\end{array}$ & $\begin{array}{c}\text { Efluente } \\
2\end{array}$ \\
\hline $\mathrm{pH}$ & 10,6 & 10,6 \\
Alcalinidade & 118 & 115 \\
$\left(\mathrm{mg} \mathrm{CaCo}_{3} \mathrm{~L}^{-1}\right)$ & 110 & 99 \\
Cor $\left(\mathrm{mg} \mathrm{Pt-Co} \mathrm{L}^{-1}\right)$ & 30 & 19 \\
Turbidez (FAU) & 251 & 337 \\
$\begin{array}{l}\text { Sólidos totais (mg L } \\
\text { Sólidos suspensos } \\
\left(\mathrm{mg} \mathrm{L}^{-1}\right)\end{array}$ & 22 & 16 \\
$\begin{array}{l}\text { Sólidos dissolvidos } \\
\left(\mathrm{mg} \mathrm{L}^{-1}\right)\end{array}$ & 229 & 321 \\
DQO (mg L & & 268 \\
\hline
\end{tabular}

\subsection{Coagulação/Floculação}

Os resultados de cor e turbidez dos ensaios de coagulação/floculação, realizados com o efluente 1, estão apresentados na Tabela 3, para cada concentração de coagulante avaliada nos diferentes valores de $\mathrm{pH}$.

O "Guia de Conservação e Reuso da Água em Edificações" estabelece para os parâmetros cor e turbidez, respectivamente, os

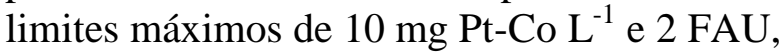
para água de reuso classe 1 .

Tabela 3 - Parâmetros do efluente 1 pré-tratado por coagulação/floculação.

\begin{tabular}{|c|c|c|c|c|c|c|}
\hline \multirow{2}{*}{$\begin{array}{c}\text { Concentração } \\
\mathrm{Al}_{2}\left(\mathrm{SO}_{4}\right)_{3} \\
\left(\mathrm{mg} \mathrm{L}^{-1}\right)\end{array}$} & \multicolumn{2}{|c|}{$\mathrm{pH} 5,0$} & \multicolumn{2}{|c|}{$\mathrm{pH} 7,0$} & \multicolumn{2}{|c|}{$\mathrm{pH} \mathrm{9,0}$} \\
\hline & $\begin{array}{c}\text { Cor } \\
\left(\mathrm{mg} \mathrm{Pt}^{\left.-C o ~ L^{-1}\right)}\right.\end{array}$ & $\begin{array}{c}\text { Turbidez } \\
\text { (FAU) }\end{array}$ & 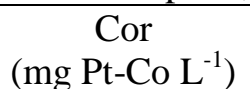 & $\begin{array}{c}\text { Turbidez } \\
\text { (FAU) }\end{array}$ & $\begin{array}{c}\text { Cor } \\
\left(\mathrm{mg} \mathrm{Pt}^{\left.-C o ~ L^{-1}\right)}\right.\end{array}$ & $\begin{array}{c}\text { Turbidez } \\
\text { (FAU) }\end{array}$ \\
\hline 100 & 8 & 0 & 1 & 1 & 0 & 2 \\
\hline 200 & 4 & 0 & 10 & 2 & 4 & 2 \\
\hline 300 & 2 & 0 & 25 & 6 & 0 & 7 \\
\hline 400 & 0 & 0 & 26 & 6 & 6 & 7 \\
\hline 500 & 5 & 2 & 23 & 6 & 6 & 8 \\
\hline 600 & 19 & 0 & 18 & 11 & 0 & 10 \\
\hline
\end{tabular}

Pelos resultados apresentados na Tabela 3 , observa-se que em $\mathrm{pH}$ 5,0 esses limites foram alcançados para as concentrações de coagulante de 100 a $500 \mathrm{mg} \mathrm{L}^{-1}$. Em pH 7,0 e
9,0 , isso ocorreu apenas para as concentrações 100 e $200 \mathrm{mg} \mathrm{L}^{-1}$.

Como o pH do efluente bruto é alcalino, optou-se por realizar a coagulação/floculação 
em $\mathrm{pH} 9,0$, pois dessa forma o volume de $\mathrm{H}_{2} \mathrm{SO}_{4}$ adicionado é menor. Além disso, a menor concentração de coagulante foi escolhida (100 $\left.\mathrm{mg} \mathrm{L}^{-1}\right)$, pois foi suficiente para fornecer os resultados de cor e turbidez dentro dos limites desejados.

Com base nesses resultados, procedeuse a coagulação/floculação do efluente da segunda coleta (efluente 2), em $\mathrm{pH} \mathrm{9,0} \mathrm{e}$ utilizando-se $100 \mathrm{mg} \mathrm{L}^{-1}$ de $\mathrm{Al}_{2}\left(\mathrm{SO}_{4}\right)_{3} \cdot 18 \mathrm{H}_{2} \mathrm{O}$. Os parâmetros analisados para o efluente 2, pré-tratado nessas condições, estão apresentados na Tabela 4.

Tabela 4 - Parâmetros do efluente 2 pré-tratado por (coagulação/floculação) com $100 \mathrm{mg} \mathrm{L}^{-1} \mathrm{de}$ $\mathrm{Al}_{2}\left(\mathrm{SO}_{4}\right)_{3} .18 \mathrm{H}_{2} \mathrm{O}$ em pH 9,0.

\begin{tabular}{|c|c|}
\hline Parâmetro & Resultado \\
\hline $\mathrm{pH}$ & 6,6 \\
\hline Cor (mg Pt-Co L $\left.\mathrm{L}^{-1}\right)$ & 0 \\
\hline Turbidez (FAU) & 2 \\
\hline $\mathrm{DQO}\left(\mathrm{mg} \mathrm{L}^{-1}\right)$ & 194 \\
\hline
\end{tabular}

Além de proporcionar remoções satisfatórias de cor e turbidez, a coagulação/floculação também reduziu a DQO em $28 \%$. Entretanto, essa redução foi inferior à remoção de $36 \%$ de DQO obtida no estudo de Šostar-Turk, Petrinić e Simonič (2005), com o mesmo coagulante e tipo de efluente.

Uma possível explicação para essa divergência está relacionada às características dos efluentes utilizados, que dependem do grau de sujidade das roupas lavadas, bem como dos produtos inseridos durante $\mathrm{o}$ processo de lavagem e tipo de amostragem realizada.

Como o valor de DQO para o efluente pré-tratado ainda se apresentou superior ao recomendado por Ciabatti et al. (2009) para reuso interno (100 $\left.\mathrm{mg} \mathrm{L}^{-1}\right)$, utilizou-se a técnica de adsorção com o intuito de se adequar também esse parâmetro.

\subsection{Adsorção}

Os experimentos de adsorção foram primeiramente realizados sem ajuste de $\mathrm{pH}$, com o efluente 2 pré-tratado por coagulação/floculação (Tabela 5).

Tabela 5 - Remoção de DQO resultante da adsorção em $\mathrm{pH}=6,6$.

\begin{tabular}{ccc}
\hline Carvão & DQO $\left(\mathrm{mg} \mathrm{L}^{-1}\right)$ & \% Remoção \\
\hline Babaçu & 115 & 40,7 \\
Dendê & 128 & 33,8 \\
Osso bovino & 113 & 41,4 \\
\hline
\end{tabular}

É possível observar que o carvão de babaçu e o carvão de osso bovino apresentaram remoções bem próximas de DQO. O carvão de dendê apresentou capacidade inferior de remoção dos poluentes contidos no efluente de lavanderia hospitalar.

As remoções de DQO para os três adsorventes foram bem baixas quando comparadas ao valor de $89 \%$ obtido na pesquisa de Šostar-Turk, Petrinić e Simonič (2005), que chegaram ao valor final de DQO de $20 \mathrm{mg} \mathrm{L}^{-1}$.

Novamente, os resultados inferiores podem estar relacionados às características dos efluentes, conforme já discutido no item 3.1. Além disso, outro fator que pode ter prejudicado a eficiência da adsorção está relacionado à área superficial dos carvões utilizados no presente estudo (Tabela 1), bem inferiores em comparação à área de $1200 \mathrm{~m}^{2} \mathrm{~g}^{-1}$ do carvão utilizado na pesquisa de Šostar-Turk, Petrinić e Simonič (2005).

Entretanto, a maior remoção de DQO ocorreu quando a adsorção foi realizada com o carvão de osso bovino, que possui a menor área superficial dentre os 3 carvões utilizados. Dessa forma, a distribuição do tamanho de poros de cada carvão provavelmente foi o fator que mais influenciou na adsorção dos poluentes.

Como os resultados obtidos não foram satisfatórios, optou-se por avaliar a influência do $\mathrm{pH}$ na redução da DQO em meios 
levemente ácidos e básicos, conforme Tabela 6.

Tabela 6 - Remoção de DQO resultante da adsorção em $\mathrm{pH}=4,0$ e pH $=10,0$.

\begin{tabular}{ccc}
\hline Carvão & DQO $\left(\mathrm{mg} \mathrm{L}^{-1}\right)$ & \% Remoção \\
\hline BH 4 & 31,0 \\
Denaçu & 134 & 15,2 \\
Osso bovino & 164 & 24,3 \\
\hline \multicolumn{3}{c}{ pH 10} \\
\hline Babaçu & 135 & 30,1 \\
Dendê & 140 & 27,7 \\
Osso bovino & 128 & 33,7 \\
\hline
\end{tabular}

É possível notar que a adsorção não foi favorecida nesses valores de $\mathrm{pH}$, pois todos os ensaios resultaram em remoções de DQO inferiores em relação ao processo realizado no $\mathrm{pH}$ do efluente pré-tratado $(6,6)$, para todos os carvões utilizados. Com isso, nenhum dos experimentos apresentou remoção de DQO suficiente para se alcançar os parâmetros para água de reuso classe 1 .

\section{CONCLUSÕES}

Com base nos ensaios de tratabilidade realizados com o efluente da lavanderia do HUM, foi possível concluir que o sistema de tratamento proposto (coagulação/floculação seguida de adsorção em carvão ativado) não foi suficiente para que os padrões exigidos para reuso do efluente no próprio processo de lavagem fossem obtidos.

Dentre os adsorventes testados, o carvão de osso bovino foi o que resultou na maior redução de DQO para o sistema de tratamento $(57,8 \%)$. Apesar do efluente tratado não ser adequado para reuso no próprio processo de lavagem, o reuso para fins menos nobres deve ser considerado. Para isso, os parâmetros estabelecidos para as demais classes de reuso devem ser avaliados, de acordo com o estabelecido pelo Guia de Conservação e
Reuso da Água em Edificações (ANA/FIESP/SINDUSCON-SP, 2005).

\section{NOMENCLATURA}

DQO: Demanda Química de Oxigênio;

HUM: Hospital Universitário Regional de Maringá.

\section{REFERÊNCIAS}

ANA/FIESP/SINDUSCON-SP - Agência Nacional das Águas/Federação das Indústrias do Estado de São Paulo/Sindicato da Indústria de Construção do Estado de São Paulo. Conservação e reuso da água em edificações. São Paulo: Prol Editora Gráfica, 2005.

APHA - American Public Health Association. Standard methods for the examination of water and wastewater. 20 ed. APHA: USA, 1998.

BRASIL. Conselho Nacional do Meio Ambiente (CONAMA). Resolução $n^{\circ} 430$, de 13 de maio de 2011. Dispõe sobre as condições e padrões de lançamento de efluentes, complementa e altera a resolução $\mathrm{n}^{0}$ 357 , de 17 de março de 2005, do Conselho Nacional do Meio Ambiente - CONAMA. Diário oficial [da União], Brasília, DF, 16 mai. 2011. p. 89.

BRASIL. Ministério da saúde. Manual de lavanderia hospitalar. Brasília. Centro de Documentação do Ministério da Saúde, 1986.

CIABATTI, I.; CESARO, F.; FARALLI, L.; FATARELLA, E.; TOGNOTTI, F. Demonstration of a treatment system for purification and reuse of laundry wastewater. Desalination, v. 245, p. 451-459, 2009.

FERREIRA, R. C.; OLIVEIRA, T. F. V.; COUTO JUNIOR, O. M.; BARROS, M. A. S. 
D.; CARVAlHO, K. Q. Mecanismo de adsorção de paracetamol em carvões de origem nacional. In: Congresso Brasileiro de Enhenharia Química, 20, 2014, Florianópolis.

KERN, D. I.; SCHWAICKHARDT, R. O.; MOHR, G.; LOBO, E. A.; KIST, L. T.; MACHADO, E. L. Toxicity and genotoxicity of hospital laundry wastewaters treated with photocatalytic ozonation. Science of the Total Environment, v. 443, p. 566-572, 2013.

KIST, L. T.; ALBRECHT, C.; MACHADO, E. L. Hospital laundry wastewater disinfection with catalytic photoozonation. Clean, v. 36, n. 9, p. 775-780, 2008.

KOVALOVA, L.; SIEGRIST, H.; SINGER, H.; WITTMER, A.; MCARDELL, C. S. Hospital wastewater treatment by membrane bioreactor: performance and efficiency for organic micropollutant elimination. Environmental Science and Technology, v. 46, p. 1536-1545, 2012.

LIU, Q.; ZHOU, Y.; CHEN, L.; ZHENG, X. Application of MBR for hospital wastewater treatment in China. Desalination, v. 250, p. 605-608, 2010.

MONARIN, M. M. S. Estudo da adsorção e dessorção do corante têxtil crimson HEXL empregando diferentes carvões ativados. 2012. 108 p. Dissertação (Mestrado em Engenharia Química) - Universidade Estadual do Oeste do Paraná, Toledo, 2012.

RICHTER, C. A. Água: métodos e tecnologia de tratamento. São Paulo: Blucher, 2009.

ŠOSTAR-TURK, $\quad$ S.; PETRINIĆ, $\quad$ I.; SIMONIČ, M. Laundry wastewater treatment using coagulation and membrane filtration.
Resources, Conservation and Recycling, v. 44, p. 185-196, 2005.

SOUZA, R. C. Tratamento de efluentes de lavanderia hospitalar para fins de reuso. 2012. Dissertação (Mestrado em Engenharia Urbana) - Universidade Estadual de Maringá, Maringá, 2012.

VERLICCHI, P.; GALLETTI, A.; PETROVIC, M.; BARCELÓ, D. Hospital effluents as a source of emerging pollutants: an overview of micropollutants and sustainable treatment options. Journal of Hydrology, v. 389, p. 416-428, 2010.

\section{AGRADECIMENTOS}

O presente trabalho foi realizado com o apoio da Coordenação de Aperfeiçoamento de Pessoal de Nível Superior - CAPES Brasil. 